\title{
MENJADI PERPUSTAKAAN ANDRAGOGI: KAJIAN PERPUSTAKAAN UNIVERSITAS INDONESIA SEBAGAI RUANG BELAJAR PENGGUNA DEWASA
}

\author{
Prisinta Wanastri \\ Jurusan Ilmu Perpustakaan dan Ilmu Informasi \\ FAH UIN Syarif Hidayatullah \\ E-mail: prisinta.wanastri@uinjkt.ac.id
}

\begin{abstract}
Andragogy is an education philosophy that refers to the method or the art of teaching and guiding adults. Popularized by Malcolm Knowles, the point of andragogical learning process relies on the view that adults are individuals who (1) are independent, (2) have life experiences that can be the foundation of learning, (3) have a desire to learn, (4) have a learning orientation appropriate to their life, and (5) have the motivation to learn. The academic library users are the academic student are an adults who has their preference on style of study, their specific needs and their own anxiety and. It is important for academic library to know preference on study style of their users, so that they can build academic to become an ideal learning spaces the adult. Becoming the center of Universitas Indonesia student Activities (especially on the learning activity) it is important for the Universitas Indonesia Library to understand the needs, characteristics and anxieties felt by the University of Indonesia students. Through this article, the authors will examine the model of adult learning of University of Indonesia students and also explained the development of Library University of Indonesia in supporting the process of adult learning in the university environment of Indonesia. This paper is based on qualitative research methods with data collection techniques such as interview, observation and literature study. Taking advantage of the phenomenological description analysis approach, the study findings show that the University of Indonesia's library is no longer merely an institution to obtain information, but also as a space for students to process the information to be learned for themselves.
\end{abstract}

Keyword: academic library, adult learning, andragogy

\section{PENDAHULUAN}

Perkembangan pendidikan perguruan tinggi saat ini sudah banyak menekankan pada pembelajaran secara mandiri yang berbasis pada penelitian. Ekspektasi pendidikan seperti ini menuntut siswa untuk mengembangkan pengetahuannya sesuai dengan kebutuhan, minat dan kemampuannya masingmasing. Pengajar atau dosen bertindak sebagai pembimbing yang mendukung kebebasan berpikir dan kebebasan gaya belajar siswanya. Sejak memulai 
pendidikan di bangku kuliah, para pendidik harus selalu menekankan pentingnya kemandirian dan tanggung jawab atas pribadi masing-masing siswa.

Dengan penekanan pembelajaran secara mandiri, memperlihatkan bahwa perguruan tinggi merupakan arena transisi bagi seseorang untuk menjadi anggota dari kelompok orang dewasa. Arti dewasa di sini, tidak hanya secara biologis, namun juga psikologis dan sosial. Menon (2016) menjelaskan bahwa siswa di perguruan tinggi memiliki kepribadian, tujuan dan kebutuhan pemenuhan informasi yang yang berbeda. Perguruan tinggi harus dapat menawarkan instruksi pembelajaran yang tidak hanya disesuaikan dengan kepribadian siswanya, namun juga menarik untuk meningkatkan motivasi siswa agar mau berusaha lebih keras dalam belajar.

Ada banyak literatur (Sheridan, 1986; Keenan, 1989; Oberman, 1991; Currie, 2000; Gold, 2005; Cooke, 2010) yang membahas penerapan teori pembelajaran orang dewasa dalam pengembangan pendidikan pengguna perpustakaan. Berbagai tulisan tersebut menjelaskan bahwa perkembangan perpustakaan akademik saat ini sudah mulai bertransformasi, bukan hanya sebagai tempat menyimpan koleksi namun juga menjadi tempat belajar untuk mengambangkan keahlian dari penggunanya. Pembelajaran dewasa, terutama dalam pendidikan pengguna perpustakaan, setidaknya dapat menjadikan pengguna membuat keputusan yang tepat, kreatif, kritis dan responsif (Burge, 1989; Knowles 1990; Galbraith, 1991).

Peran perpustakaan akademik dalam mendukung pendidikan dewasa untuk penggunanya, bukan sekedar memberikan tempat belajar namun juga harus didukung dengan kemampuan pustakawan yang dapat memfalisitasi kemandirian belajar para penggunanya. Menempatkan perpustakaan sebagai ruang belajar, memberikan tekanan bagi pustakawan untuk bertindak bukan sekedar menjadi pustakawan rujukan namun lebih menjadi penasehat ataupun konsultan informasi bagi pengguna (Brophy, 2005). Perilaku belajar mandiri, meningkatkan kebutuhan informasi pengguna menjadi lebih luas namun mendalam. Hal ini menambah tugas pustakawan untuk mempertimbangkan penggunaan informasi dari luar dan memberikan masukan atas informasi yang dibutuhkan pengguna, untuk memenuhi kebutuhan khusus dari penggunanya. 
Walaupun tidak sepenuhnya, metode pembelajaran di Universitas Indonesia sudah mulai mengarah pada bentuk pembelajaran dewasa. Dalam pelaksanaan perkuliahan, pengajar di Universitas Indonesia sudah condong bertindak sebagai seorang yang lebih pada membantu pengembangan keterampilan siswanya daripada mentransmisikan isi disiplin ilmu yang diajarnya (Wilson, 1994). Dengan model pendidikan seperti itu, siswa dituntut untuk mendalami keilmuan yang dipelajarinya secara mandiri. Mencari data, mengolahnya menjadi informasi dan menganalisisnya menjadi kajian yang sesuai dengan bidang keilmuannya, menjadi tanggung jawab pribadi dari masingmasing siswa.

Perpustakaan Universitas Indonesia, secara perlahan mulai mengembangkan layanannya dalam mendukung proses belajar mengajar bagi siswa Universitas Indonesia. Siswa UI merupakan kelompok dewasa yang bertanggung jawab atas kegiatan belajarnya secara pribadi dan harus mampu harus mampu menilai kemampuannya sendiri. Oleh karena itu, perpustakaan Universitas Indonesia setidaknya dapat mendukung kegiatan belajar kolaboratif, yang membantu siswa dapat berefleksi dan menjadi pribadi yang independen.

\section{METODE PENELITIAN}

Penelitian mengenai Perpustakaan Univeritas Indonesia sebagai perpustakaan yang mendukung konsep pembelajaran anragogi merupakan refleksi pengalaman dari penulis dalam memanfaatkan layanan Perpustakaan Universitas Indonesia. Penelitian ini dilakukan sebagai upaya peneliti dalam menginterpretasi dan mengkritisi layanan yang ditawarkan oleh Perpustakaan Universitas Indonesia. Dalam penelitian ini, peneliti melihat Perpustakaan Universitas Indonesia tidak hanya sebagai tempat menyimpan koleksi, namun juga menjadi ruang belajar yang efektif bagi penggunanya, yang disesuaikan dengan model belajar dari penggunanya. Oleh karena itu, untuk mendapatkan gambaran mengenai pola-pola dan bentuk layanan Perpustakaan Universitas Indonesia sebagai ruang belajar, peneliti menggunakan pendekatan kualitatif sebagai metode penelitian. 
Pendekatan kualitatif merupakan metode mengidentifikasi sebuah gejala sosial atau sebuah fenomena yang terjadi dalam suatu kelompok masyarakat dari kaca mata kelompok masyarakat yang diteliti (Cresswell, 1994). Oleh karena itu dalam penelitian ini, hasil analisis dari rumusan masalah yang diangkat, sesuai dengan kejadian yang terjadi di Perpustakaan Universitas Indonesia. Peneliti berusaha memisahkan pandangan yang subjektifitas atas masalah penelitian yang diangkat dan menganalisis secara objektif berdasarkan keadaan yang terjadi di lapangan. Hasil analisis peneliian didasarkan pada hasil observasi dan wawancara peneliti terhadap kegiatan pustakawan dan siswa yang aktif menggunakan layanan Perpustakaan Universitas Indonesia.

\section{HASIL DAN PEMBAHASAN}

\section{Siswa Universitas Indonesia sebagai Kelompok Dewasa}

Dengan jargon "Crystal of Knowledge" perpustakaan Universitas Indonesia berusaha bertindak sebagai jantung yang mendukung pelasanaan program pendidikan di Universitas Indonesia. Perpustakaan Universitas Indonesia berkembang untuk mendukung kegiatan belajar mengajar siswa Univeritas Indonesia secara penuh. Layanan yang ditawakan oleh Perpustakaan Universitas Indonesia, sepenuhnya didasarkan pada kebutuhan dari pengguna perpustakaan, teutama civitas akademi Univeritas Indonesia.

Berdasarkan hasil observasi dan wawancara dengan beberapa pengguna perpustakaan, pemanfaatan layanan perpustakaan di Universitas Indonesia bukan sekedar untuk mencari informasi, namun juga untuk mengolah dan mengatikulasikannya ke dalam berbagai bentuk laporan proyek perkuliahan ataupun penelitian pribadi. Keinginan untuk belajar, bagi para siswa ini bukan hanya berasal dari tugas kuliah namun memang ada yang sengaja belajar dan berdikusi terkait dengan hal-hal lain yang memang menarik bagi dirinya.

Membaca, mengerjakan tugas secara pribadi ataupun dan berdikusi merupakan kegiatan yang paling umum terlihat di Perpustakaan Universitas Indonesia. Menurut pengguna perpustakaan, belajar dengan berdiskusi di luar kelas dapat mempeluas pengetahuan mereka atas permasalahan yang dihadapinya. Selain itu diskusi dapat membantu mereka untuk mengartikuliasikan 
permasalahan yang mereka hadapi dan juga lebih kuat tertatanam dalam ingatan mereka.

\section{Perpustakaan Universitas Indonesia sebagai Perpustakaan Andragogi}

\section{a. Penyediaan Petunjuk Bibliografi yang Baik}

Berdasarkan hasil observasi peneliti, siswa Universitas Indonesia cenderung memiliki sikap yang skeptis terhadap layanan perpustakaan, terutama untuk yang berinteraksi langsung dengan pustakawan. Para siswa ini cenderung berfikiran untuk menacari bahan pustaka bersikap mandiri tanpa perlu berinteraksi dengan pustakawan yang tidak dikenalnya. Permasalahan ini sudah dibaca oleh pihak Perpustakaan Universitas Indonesia itu sendiri, hal ini kemudian menjadi acuan bagi Perpustakaan Universitas Indonesia untuk mengadakan programprogram pelatihan literasi informasi yang dapat diakses oleh seluruh sivitas akademik UI setiap tahunnya. Konten pelatihan literasi informasi yang diberikan oleh Perpustakaan Universitas Indonesia mencakup pengenalan perpustakaan secara umum, cara memanfaatkan layanan perpustakaan, pengajaran penggunaan OPAC perpustakaan dan pengenalan literasi koleksi perpustakaan baik yang tercetak ataupun yang digital.

Dengan adanya pelatihan literasi ini, siswa Universitas Indonesia dapat mengakses informasi secara lebih luas dan mendalam. Pelatihan ini membantu siswa untuk mengembangakan kemampuannya, tanpa meminta bantuan dari pustawakawan mereka dapat memeroleh informasi yang bernilai secara mandiri. Siswa yang pernah mengikuti pelatihan literasi ini beranggapan bahwa komponen-komponen pelatihan yang diberikan cukup bermanfaat bagi mereka, dan tentunya dapat diaplikasikan bukan hanya untuk mengakses informasi dari dalam perpustakaan namun juga di luar perpustakaan.

\section{b. Ruang Belajar yang Ideal}

Perpustakaan Universitas Indonesia terdiri dari berbagai macam ruang fisik dengan karakter yang berbeda-beda. Karakter ruangan perpustakaan tersebut, secara kasat mata, dibangun melalui penggunaan benda-benda fisik yang berbeda di setiap ruangan. Mebel dengan benda fisik pendukung lainnya hadir sebagai 
sebuah ciri dari setiap ruang di perpustakaan. Jika kita merujuk pada pendapat Dovey (1999), dapat diketahui bahwa bentuk mebel yang diletakkan dengan polapola tertentu, secara tidak langsung mampu mempengaruhi kegiatan yang dilakukan para pengguna di dalam ruangan.

Secara garis besar pembagian berbagai ruang perpustakaan yang terdiri dari ruang baca, ruang diskusi dan ruang koleksi, ditunjukkan untuk kegiatan belajar, baik mandiri maupun ataupun bersama-sama, baik untuk sekedar sebagai tempat ataupun untuk berdikusi. Pembagian ruangan ini memberikan kenyamanan bagi siswa, karena mereka dapat memilih metode belajar yang ideal bagi mereka tanpa harus merasa terganggu dengan kondisi sekitarnya. Saat siswa ingin belajar sendiri pembelajarannya bersifat pribadi, mereka dapat memanfaatkan ruang baca dan ruang koleksi. Sedangkan apabila mereka ingin belajar bersama-sama dan sifatnya adalah diskusi, mereka dapat memanfaatkan ruang diskusi. Selain itu siswa juga dapat memanfaatkan layanan komputer untuk mengerjakan tugas di lab komputer.

\section{c. Hadirnya Pustakawan Rujukan sebagai Fasilitator}

Pustakwan rujukan di Perpustakaan Universitas Indonesia memiliki peran sebagai fasilitator. Kegiatan yang memperlihatkan pustakawan sebagai fasilitator adalah bahwa dalam melaksanakan perannya dalam merujuk informasi bagi siswa, pustakawan rujukan ini juga sering kali diajak berdiskusi oleh siswa. Dalam hal ini, kemampuan pustakawan bukan sekedar memberikan informasi yang ideal bagi siswa, namun juga turut mengkaji bersama atas permasalah yang dihadapi siswa baik itu dalam ranah teoretis dan praktis.

Sebagai fasilitator, pustakawan mempelajari secara mendalam permasalahan yang dihadapi siswa, mempelajari sumber informasi yang dibutuhkan siswa secara mendalam sehingga mereka dapat merespon lebih baik dalam melayani siswa, namun juga banyak memberikan masukan-masukan lebih lanjut kepada siapa saja para siswa ini dapat berkonsultasi, metode pembelajaran yang paling baik bagi siswa, dll. Dalam mewujudkan pustakawan rujukan sebagai fasilitator, tentunya latar belakang pendidikan dari pustakawan bukan sekedar ilmu perpustakaan, namun juga berlatar belakang ilmu atau kajian yang memiliki 
basis yang sama dengan siswanya. Oleh karena itu setiap pustakawan tujukan memiliki spesialisasi bidang keilmu yang mereka layani.

\section{PENUTUP}

Berdasarkan paparan di atas, dapat dikemukakan bahwa pada dasarnya peran perpustakaan perpustakaan akademik untuk mendukung proses belajar mengajar kelompok dewasa memerlukan koordinasi layanan yang menyeluruh. Bukan hanya sebatas pengembangan teknologi, ataupun pengembangan sdm perpustakaan, atau bahkan hanya sekedar penyediaan ruang belajar. Bila dikaitkan dengan kegelisahan-kegelisahan yang dihadapi siswa dewasa dalam memanfaatkan layanan perpustakaan dapat diselesaikan dengan memberikan (1) petunjuk-petunjuk bibliografi perpustakaan yang baik, (2) menyediakan ruangruang belajar yang memiliki fungsi dan karakter yang berbeda-beda sehingga siswa dapat memilih ruangan yang ideal untuknya, untuk dimanfaatkan sebagai ruang belajar yang ideal bagi mereka dan (3) menghadirkan pustakawan yang dapat bertindak sebagai fasilitator, pembimbing siswa di luar tenaga pengajar.

\section{DAFTAR PUSTAKA}

Applegate, R. (2009) The Library is For Studying: Student Preferences for Study Space. Journal of Academic Librarianship , 35 (4), 341-346.

Brennan, Terrence F. (2009) A Grounded Theory of the Effects of a Bibliographic Instruction Course on Adult Learning. Diss. University of WisconsinMadison, Ann Arbor: UMI

Brophy, P. (2005) The Academic Library. London: Facet Publishing.

Burge, Elizabeth J. and others. (1989). Developing partnerships: An investigation of library-based relationships with students and educators participating in distance education in Northern Ontario. Toronto: Ontario Institute for Studies in Education.

Cresswell, J. W. (1994). Research Design: Qualitative and Quantitative Approaches. London: Sage Publication.

Cooke, Nicole A. (2010) Bcoming an andragogical librarian: using Library Instruction as a tol to combat library anxiety and empower adult learners, New Review of Academic Librarianship, 16:208-227 DOI: $10.1080 / 13614533.2010 .507388$ 
Currie , C. Lyn (2000) Facilitating Adult Learning: The Role of the Academic Librarian, The Reference Librarian, 33:69-70, 219-231, DOI: 10.1300/J120v33n69_21

Dovey, K. (1999). Framing Places. London: Routledge.

Gold, Helene E (2005) Engaging the Adult Learner: Creating Effective Library Instruction. Portal : Libraries and the Academy; Oct 2005; 5, 4; Research Library pg. 467

Galbraith, M.W. (1989). Essential skills for the facilitator of adult learning. Lifelong learning: An omnibus of practice and research 12, 6, 10-13.

Gayton, J. T. (2008). Academic Libraries: "Social" or "Communal?" The Nature and Future of Academic Libraries. Journal of Academic Librarianship , 34 (1), 60-66.

Grassian, Esther S., and Joan R. Kaplowitz. Information Literacy Instruction: Theory and Practice. New York: Neal-Schuman Publishers, Inc., 2001.

Jarvis, P. (1985) The Sociology of Adult and Continuing Education, Beckenham: Croom Helm.

Jolly, L. (2012). Space: Changing the Boundaries. Dalam M. Melling, \& M. Weaver (Penyunt.), Collaboration in Libraries and Learning Environment (hal. 129-148). London: Facet Publishing

Keenan, Lori(1989). Andragogy off-campus: The library'srole. Reference Librarian 24, 147-158

Knowles, M. (1980). The modern practice of adult education: From pedagogy to andragogy. New York: Cambridge.

Knowles, M. (1990). The adult learner: A neglected species. 4th ed. Houston: Gulf Publishing.

Knowles M., et al. (2005) The Adult Learner: The Definitive Classic in Adult Education and Human Resource Development. 6th edition. Amsterdam: Elsevier.

Jiao, Qun G., and Anthony J. Onwuegbuzie. (1997) Antecedents of Library Anxiety. Library Quarterly: 372-89.

Liangjindathavorn, O. (1997). A study of relationship between library use behaviors and study performances of Ubon Ratchathani University students. UbonRatchathani: The University Library 
Mackeracher, D.(1996). Making sense of adult learning.Toronto: Culture Concepts.

Mennon, Mohandas (2016) Higher Education Pedagogy: Theoretical Basis for Developments in Practice. Emerging Trends in Higher Education Pedagogy. Penang: WOU Press

Oberman, Cerise and Linton, Rebecca A. (1982). Guided design: teaching library research as problem-solving. In Oberman, Cerise and Strauch, Katina (Eds.) Theories of bibliographic education: Designs for teaching. New York: Bowker.

Sheridan, Jean (1986). Andragogy: A newconcept for academic librarians. Research Strategies 4, 4, 156-167.

Wilson, Vicky (1994). Developing the adult independent learner: Information literacy and the remote external student. Distance Education 15, 254-279. 